\title{
Yetişkinlerde Travma Sonrası Stres ve Öz Duyarlılığın Travma Sonrası Büyüme Üzerindeki Yordayı1cı Rolü
}

\author{
DOI: 10.26466/opus.594006
}

*

\begin{abstract}
Neslihan Arıcı Özcan*
Dr. Öğr. Ü., İstanbul Medeniyet Üniversitesi, Sosyal Hizmet Bölümü, İstanbul / Türkiye E-Posta: neslihan.ozcan@medeniyet.edu.tr ORCID: 0000-0002-6169-1445 Öz
\end{abstract}

$B u$ araştırmada amaç, yetişkin bireylerde görülen travma sonrası stres, travma sonrası büyüme ve öz duyarlılık arasındaki ilişkiyi incelemektir. Araştırmada veri toplamak için Travma Sonrası Stres Bozukluğu Ölçeği, Öz Duyarlllık Ölçeği ve Travma Sonrası Büyüme Ölçeğgi kullanılmıştır. Araştırmanın çalışma grubunu, İstanbul Medeniyet Üniversitesi Sağllk Bilimleri Fakültesi Sosyal Hizmet Bölümü öğrencileri ve onların yetişkin aile bireyleri oluşturmaktadır. Çalışma grubunda 426 kadın $(\% 75,9), 135$ erkek $(\% 24,1)$ toplam 561 katılımcı yer almaktadır ve katılımcıların yaşları 18-67 (X=25.26) aralı̆̆ında değişmektedir. Araştırmanın verilerinin analizinde korelasyon ve regresyon analizi yöntemlerinden faydalanılmışıı. Araştırmanın sonuçları, travma sonrası stresin ve öz duyarlılı̆̆ın travma sonrası büyüme ile anlaml düzeyde ilişkili olduğunu göstermektedir. Ayrıca travma sonrası stresin ve öz duyarlılı̆̆ın travma sonrası büyümeyi anlamlı ve pozitif yoüde yordadığı bulunmuştur. Bulgular ilgili alanyazı doğrultusunda tartışılmış ve çeşitli öneriler sunulmuştur. Son yıllarda dünyada giderek artmakta olan giderek artan travmatik yaşantılar karşısında travma sonrası stresin ve öz duyarlılı̆̆ın travma sonrası büyümeyi açıklaması ile bu çalışmanın, literatüre önemli bir katkı sağladığı öne sürülebilir.

Anahtar Kelimeler: Yetişkinler, Travma Sonrası Stres, Öz Duyarlılık, Travma Sonrası Büyüme 


\title{
The Predictive Role of Posttraumatic Stress and Self Compassion on Posttraumatic Growth
}

*

\begin{abstract}
The aim of this study is to investigate the relationship among posttraumatic stress, posttraumatic growth and self-compassion in adult individuals. Post-traumatic Stress Disorder Scale, Self-Compassion Scale and Post-traumatic Growth Scale have been used to collect data. The study group has been gathered from the students at Faculty of Health Sciences in Istanbul Medeniyet University and their adult family members. The study group included total 561 participants, 426 women (75.9\%) and 135 men $(24.1 \%)$. The study group ranged in age from 18 to 67 years ( $X=25.26)$. Correlation and regression analysis methods have been used in the analysis of the data. As a result of the study, post-traumatic stress and self-compassion have been significantly correlated with post-traumatic growth. In addition, post-traumatic stress and self-compassion have a predictor role in post-traumatic growth, significantly and positively. The findings have been discussed in accordance with the related literature and various suggestions were presented. This study may have an important contribution to the literature by indicating that in the face of increasing traumatic experiences in the world, post-traumatic stress and posttraumatic growth explains self-compassion.
\end{abstract}

Keywords: Adults, Post-Traumatic stress, self-compassion, post-traumatic growth 


\section{Giriş}

Günümüzde birçok psikolojik rahatsızlık travmaya maruz kalmaya bağlı olarak ortaya çıkmaktadır (Zatzick ve ark., 2007). Travmaya maruz kalan bireylerin çoğunda travma sonrası stres bozukluğu görülmektedir (Kessler, 2000; Kessler ve ark., 2014). Amerikan Psikiyatri Birliği Ruhsal Bozuklukların Tanısal ve İstatistiksel el kitabının (2013) tanımına göre travma sonrası stres bozukluğu, gerçek bir ölüm veya ölüm tehdidinin bulunduğu, bireyin kendisinin yaşadığı ya da şahit olduğu bir ağır yaralanmanın veya fiziksel bütünlüğe yönelik bir tehdidin sonucunda oluşan, bireyde temel olarak yoğun kaygı duygusu yaşatan ve bireyin işlevini ciddi anlamda bozan bir bozukluktur. Bireyin travma sonrası stres bozukluğu yaşamasını açıklayan birçok kuram ve model [duygu işleme modelleri (Foa, Huppert ve Cahill, 2006; Rauch ve Foa, 2006), bilişsel modeller (Brewin ve Holmes, 2003; Clark ve Ehlers, 2004; Dalgleish, 2004; Park, Mills ve Edmondson, 2012), kaynak modeli (Benight ve ark., 2000; Hobfoll, Tracy ve Galea, 2006; Ironson ve ark., 1997)] bulunmaktadır. Bu modellerde ortak olarak travmanın bireysel içsel değerlendirme süreçlerinde duyarlılık yarattığı (Maheux ve Price, 2016) ve ayrıca travmanın psikososyal bir sistem içerisinde bireysel özelliklerin ve farklılıkların etkileşimine (kişilik, bilişsel değerlendirme, başa çıma becerileri) odaklanılarak (Joseph, Williams ve Yule, 1997) ele alınması gerektiği vurgulanmıştır. Travma sonrası stres hem psikososyal sistem içerisinde hem de bireyin içsel değerlendirmelerindeki duyarlılıkları ile ele alındığında travmanın olumlu etkileri görülebilmektedir (Joseph ve Linley, 2005). Bu duyarlılıkta içsel ve dışsal kaynaklarını fark eden ve kullanan bireylerde travmanın olumlu etkileri görülebilmektedir (Maheux ve Price, 2016).

Travma sonrası büyüme, bireyin zorlu yaşam deneyiminde olumlu psikolojik değişimi deneyimlemesidir (Tedeschi ve Calhoun, 2004). Travma sonrası büyümenin gerçekleşmesi için bireyin orta düzeyde travma sonrası stres belirtileri göstermesi gerekmektedir (Bleich, Gelkopf ve Solomon, 2003; Dekel ve Hobfoll, 2007; Helgeson, Reynolds ve Tomich, 2006; Laufer ve Solomon, 2006). Travma sonrası stres ile travma sonras1 büyüme arasında ters $U$ şeklinde bir ilişki bulunmaktadır (Colville ve Cream, 2009; Ehlers ve Clark, 2000; Kunst, 2010). Travma sonrası stresi 
açıklayan kuramlarda bireyin zorlu deneyimle başa çıkarken bilişsel olarak sorguladığ (araya girici düşünceler) ve bu sorgulamalar neticesinde çeşitli stratejiler (kaçınma ve uyarılma) geliştirdiği ifade edilmektedir. Bütün bu bilişsel ve davranışsal durumlar bireyin kendilik algısı, ilişkiler ve yaşam felsefesinde değişiklikler yaratıp travma sonrası büyüme yaşamasına yol açabilmektedir (Janoff-Bulman, 2006). Travma sonrası büyümedeki bu değişimleri psikososyal yaklaşım içinde birçok çalışma (Armeli, Gunthert ve Cohen, 2001; O'Leary ve Ickovics, 1995; Tedeshi ve Calhoun, 1995; Waysman, Schwarzwald ve Solomon, 2001) ele almaktadır. Psikososyal yaklaşımlar ile ele alınan çalışmalarda travma sonrası büyüme; duygusal, bilişsel ve kaynak kullanımı ile değerlendirilmektedir. Psikososyal yaklaşımlarla ele alınan çalışmalarda, travmadan etkilenirken bireyin hem aldığı sosyal destek kaynaklarından hem de kişisel özelliklerinden (özerlik, ilişkide olma vb.) dolayı yaşadığı zorlu olayın üzerinde düşünmesi, anlaması, ona göre yeni düzenlemeler yapması, bireyin yaşadığ 1 travmatik olaydan büyüyerek çıkmasını sağladığı vurgulanmaktadır (Calhoun ve Tedeschi, 2014; Joseph ve Linley, 2005; Joseph, Murphy ve Regel, 2012).

Bireyin yaşamında yeni düzenleme yapabilmesi, içsel ve dişsal kaynaklarını kullanabilmesi için de yaşanılan olayı kabul etmesi önemlidir (Bomyea, Risbrough ve Lang, 2012). Bu bağlamda bireyin yaşanılan olayı anlaması ve kabul etmesini açıklayabilecek önemli kavramlardan bir tanesi de öz duyarlılıktır. Öz duyarlılık bireyin kendi yaşadığı zorluklara, zorluklar karşısında yaşadığı acılara ve duygulara açık olması, bunları şefkatli ve ön yargısız bir şekilde kabul etmesidir (Neff, 2003a; Neff ve McGehee, 2010; Neff ve Vonk, 2009). Öz duyarlılık bireyin kendi deneyimlerini herkesin yaşayabileceği ortak insanlık deneyimi olarak algılamasını sağlamaktadır. Zorlayıcı yaşantının ortak bir insan deneyimi olarak algılanması zorlayıcı yaşantı karşısında psikolojik sorunlar yaşanmasını önleyebilmektedir (Barnard ve Curry, 2011; Seligowski, Miron ve Orcutt, 2015; Zeller, Yuval, Nitzan-Assayag ve Bernstein, 2015). Bu bağlamda travma ile öz duyarlılık arasında negatif bir ilişki vardır. Öz duyarlılık, bireyin yaşadığı travmatik olayı algılamasını olumlu yönde etkileyip bireyin travmatik olayla daha sağlıklı başa çıkmasını ve travma yaşamamasını sağlayabilir. Ayrıca öz duyarlılığın; bireyin travma karşısında ihtiyaçlarının farkına varmasına ve bu ihtiyaçlarını karşılamak için sosyal destek 
aramasına (Allen ve Leary, 2010; Germer ve Neff, 2015; Neff, 2003a), yaşadığı deneyimdeki acı veren duyguları ve düşünceleri deneyimlemesine (Thompson ve Waltz, 2008), deneyimlemeye izin verdiği için kendini daha az suçlamasına (Gilbert ve Procter, 2006; Raes, 2010) ve böylelikle de travmayı kendini değiştiren bir deneyim olarak algılamasına (Kross ve Ayduk, 2011; Maheux ve Price, 2016) yol açtığı ifade edilmektedir. Ayrıca birçok çalışmada öz duyarlılığın yüksek olması ile kişilerin psikolojik sağlığının yakından ilişkili olduğu gösterilmektedir (Neff, 2004; Neff ve Vonk, 2009). Bütün bunlar öz duyarlılığın bireyin travmayı daha sağlıklı ele almasını sağladığını ve hatta öz duyarlılığın travma sonrası büyümedeki rolünü de destekler niteliktedir.

Sonuç olarak, bu çalışmada üzerinde durulan araştırma sonuçları, yetişkinlerin travma sonrası büyüme yaşamalarında travma sonrası stres düzeylerinin ve öz duyarlılığın önemli role sahip olduğunu göstermektedir. İlgili alanyazın incelendiğinde, travma sonrası stres ve öz duyarlılı̆̆ın çeşitli değişkenler ile ilişkilerinin incelendiği ancak travma sonrası büyüme ile birlikte az sayıda çalışma (Maheux ve Price, 2016; Wong ve Yeung, 2017) da olduğu görülmüştür. Buna paralel olarak bu araştırmadan elde edilen sonuç doğrultusunda araştırmacılar ve alandaki uzmanlar için travma sonrası stres yaşayan bireylerin travma sonrası büyüme gösterebilmeleri için öz duyarlılık odaklı programların ve eğitimlerin hazırlamalarına betimsel bir dayanak olabilir. Buradan hareketle bu çalışmada travma sonrası stres ve öz duyarlılı̆̆ın travma sonrası büyümeyi yordayıp yordamadığı incelenmiştir.

Yukarıda belirtilen amaç doğrultusunda araştırmanın denenceleri şu şekildedir.

- H1: Travma sonrası stres düzeyi ile travma sonrası büyüme düzeyi arasında bir ilişki vardır.

- $\mathrm{H}_{2}$ : Öz duyarlılık düzeyi ile travma sonrası büyüme düzeyi arasında bir ilişi vardır

- $\mathrm{H}_{3}$ : Travma sonrası stres düzeyi ile öz duyarlılık düzeyi arasında bir ilişi vardır

- $\quad \mathrm{H}_{2}$ Travma sonrası stres düzeyi ve öz duyarlılık düzeyi travma sonrası büyümeyi yordamaktadır. 


\section{Yöntem}

\section{Araştırma Modeli}

Araştırma ilişkisel tarama modeli kullanılarak yapılan betimsel nitelikte bir çalışmadır. İlişkisel tarama modeli, iki ve daha çok sayıdaki değişken arasında birlikte değişimin varlığını ve/veya derecesini belirlemeyi amaçlayan araştırma modelidir (Karasar, 2012).

\section{Çalışma Grubu}

Araştırmada verileri, İstanbul Medeniyet Üniversitesi Sağlık Bilimleri Fakültesi Sosyal Hizmet Bölümü öğrencileri ve onların yetişkin aile bireylerinden kartopu yöntemi ile 2018 Şubat-2018 Mayıs ayları arasında toplanmıştır. Araştırmaya toplam 561 yetişkin birey katılmıştır. Katılımcıların yaşları 18-67 (x=25.26) aralığında değişmektedir. Çalışma grubunda 426 kadın $(\% 75,9)$ ve 135 erkek $(\% 24,1)$ yer almaktadır. Araştırmaya katılan katılımciların \%56,4'ü (N=314, \%56,4) lise mezunu, \%28,5'i üniversite mezunu (N=159), \%7,4'ü ilkokul mezunu (N=41), \%3,1'i (N=17) ortaokul mezunudur. Araştırmaya katılan katılımcıların çoğu, genç yetişkinlikte olduğundan dolayı bekardır $(\mathrm{N}=415, \% 75,8)$ ve maddi olarak orta derece sosyo-ekonomik seviyede yer aldıklarını belirtmişlerdir. Araştırmaya ka-

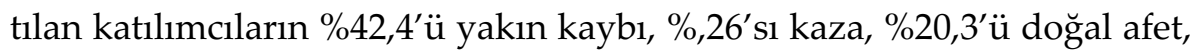
\%6,7'si terör olayları, \%1,3' ̈̈ de yaşamı tehdit eden hastalığı travma olarak belirtmiştir. Ayrıca araştırmaya katılan katılımcıların \%40,6'sı sadece bir travmatik yaşantı belirtirken, \%26,9’u iki, \%15,2'si üç, \%6,8'si dört travma sayısı belirtmişlerdir.

\section{Veri Toplama Araçlan}

Travma Sonrası Stres Ölçeği (TSSÖ):Foa, Cashman, Jaycox ve Perry tarafından (1997) geliştirilen, Türkçe' ye uyarlaması ise Işıklı ve Dürü tarafından gerçekleştirilen TSSÖ (2006) travma sonrası stres bozukluğunu belirlemek amaçlı bir öz-bildirim ölçeğidir (Foa ve ark., 1997). Ölçeğin orijinali dört bölümden oluşmaktadır. İlk bölüm, kişinin yaşadı̆̆ı travmatik olayın 
türünü (doğal afet, kaza, savaş, tecavüz gibi) belirlemektedir. İkinci bölüm, birden fazla travmatik olaydan kişiyi en fazla etkileyen yaşantıyı belirlemektedir. Üçüncü bölümde, 17 maddeden oluşan ve travma sonrası stres belirtileri değerlendiren bir alt ölçek bulunmaktadır. 17 maddelik alt ölçek 0-3 Likert tipli bir öz-bildirim ölçeğidir. 17 maddelik ölçekten alınacak minimum puan 0 , maksimum puan 51'dir. Ölçeğin son bölümünde, travmatik olayın kişinin yaşamı üzerindeki etkisini belirlemeye yönelik, evet-hayır şeklinde yanıtlanan 9 soru yer almaktadır. Travma belirtilerinin şiddetini ölçmeyi amaçlayan 17 maddelik ölçeğin orijinal formunun iç tutarlılığı $\alpha=0.92^{\prime}$ dir. Test-tekrar test güvenirlik katsayısı da .83'tür (Foa ve ark., 1997).

Işıklı ve Dürü (2006) tarafından Türkçe'ye adapte edilen ölçeğin iç tutarlılığ 1 ise $\alpha=.93^{\prime}$ dür. Madde-toplam test korelasyon katsayılarının da 0.39 ile 0.82 arasında değiştiği belirtilmiştir. Test maddelerinin önceden bilinen bu 3 faktöre yüklenip yüklenmedikleri Temel Eksenler Faktörlemesi (Principal Axis Factoring) ve Varimax rotasyonu kullanılarak sorgulanmıştır. Bu analiz sonucunda 2 madde dişında (6. ve 7. maddeler) tüm maddelerin kuramsal olarak bulunmaları gereken faktörlerin altına yüklendikleri saptanmıştır. Bu iki maddenin "yeniden yaşama" faktörüne yüklenmeleri gerekirken, "aşırı irkilme" faktörüne yüklendikleri görülmüştür. Yapılan faktör analizi sonucunda bu üç faktörün, toplam varyansin \%59'unu açıkladığı görülmüştür. Ölçeğin Travma Sonrası Stres Belirtilerini ölçen üçüncü alt ölçeğinin diğer ölçeklerle ilişkisi, Kısa Semptom Envanteriyle .70, Beck Depresyon Ölçeğiyle .60 ve Beck Anksiyete Ölçeğiyle .63 düzeyinde korelasyonu olduğu görülmektedir.

Travma Sonrası Büyüme Ölçeği (TSBÖ):Tedeschi ve Calhoun (1996) tarafından geliştirilen ve Dürü (2006) tarafından Türkçe'ye adapte edilen ölçek travmatik yaşantı sonrası büyümeyi ölçen, 21 maddelik ve 6 Likertli (0-5) derecelendirmeye dayalı olarak cevaplanan bir öz-bildirim ölçeğidir. Ölçek, Başkalarıyla İlişkiler, Yeni Fırsatlar, Kişisel Güçlülük, Manevi Değişim ve Yaşamı Takdir Etme olmak üzere 5 alt boyuttan oluşmaktadır. Ölçeğin puanlaması sonucunda ise, alınabilecek an düşük puan 0 ve en yüksek puan ise 105' dir. 
Ölçekten elde edilen puanın yüksek olması, bireyin travmatik yaşantı karşısında büyüme düzeyinin yüksekliğini göstermektedir. Ölçeğin orijinalindeki (Tedeschi ve Calhoun, 1996) iç tutarlı̆̆ $\propto \propto=.90$ düzeyinde olduğu belirtilmektedir. Alt testlerinin iç tutarlılığ ise $\propto=.66$ ve $\propto=.85$ arasında değişmektedir. Test-tekrar test güvenirliği için yapılan çalışmada korelasyon katsayısı .71 olarak ifade edilmiştir. Ayrıca orijinal ölçeğin iyimserlik, dinsel katılım, dışadönüklük, deneyimlere açıklık, uyumluluk ve vicdanlılık gibi değişkenlerle pozitif yönde anlamlı ilişkisi olduğu ifade edilmiştir. Geçerlilik çalışması için faktör analizinde ise orijinal ölçeğin beş alt boyutlu olduğu (Başkalarıyla İlişkiler, Yeni Fırsatlar, Kişisel Güçlülük, Manevi Değişim ve Yaşamı Takdir Etme) tespit edilmiştir. Türkçe'ye adapte edilen ölçeğin ise iç tutarlık katsayısı $\propto=.93$ olarak hesaplanmıştır. Çalışmada, ölçeğin yapı geçerliğine Temel Eksenler Faktörlemesi ve Varimax rotasyonu ile bakılmış ve beş faktörlü bu çözümde varyansın \%67,84'ünün açılanabildiği belirtilmiştir. Bu bulgular ışığında Travma Sonrası Büyüme Ölçeğinin kabul edilebilir düzeyde geçerli ve güvenilir olduğu sonucuna varılmıştır

Öz-duyarlılık Ölçeği (ÖDÖ):Neff (2003a) tarafından geliştirilen ve Akın, Akın ve Abacı tarafından (2007) Türkçe'ye adapte edilen ölçek, öz duyarlılığ1 ölçen 26 maddelik ve 5'li Likert tipi cevaplamaya dayalı bir öz bildirim ölçeğidir. Öz-duyarlık ölçeği için yapılan DFA'da, öz-duyarlılık yapısını oluşturan 6 alt boyutun varlığı doğrulanmıştır: Öz-sevecenlik/öz-yargılama, paylaşımların bilincinde olma/yabancılaşma ve bilinçlilik/aşırıözdeşleşme. Ölçeğin orijinal formundaki alt ölçeklere ilişkin madde faktör yüklerinin, i, öz-sevecenlik için .71-.77, öz-yargılama için .65-.80, paylaşımların bilincinde olma için .57-.79, yabancılaşma için .63-.75, bilinçlilik için .62-.80 ve aşırı-özdeşleşme için .65-.78 arasında değişmektedir. Orijinal ölçeğin iç tutarlılık güvenirlik katsayıları alt ölçekler için sırasıyla .78, $.77, .80, .79, .75$ ve .81 'dir. Tekrar test güvenirlik katsayıları ise sırasıyla .88 , $.88, .80, .85$, .85 ve .88 olarak bulunmuştur (Neff, 2003a). Öz duyarlılık ölçeğinin Türkçe versiyonunun yapı geçerliği için AFA ve DFA yapılmıştır. Ölçeğin AFA'da KMO örneklem uygunluk katsayısı .66, Barlett Sphericity testi $\chi 2$ değeri ise 15464.500 ( $p<.001$ ) bulunmuştur. Yapılan analiz sonucunda toplam varyansın \%68' ini açıklayan, 26 madde ve 6 alt ölçekten olu- 
şan bir ölçme aracı elde edilmiştir. Ayrıca alt boyutlarda yer alan maddelerin orijinal formla örtüştüğü görülmüştür. Ölçeğin alt ölçekleri için elde edilmiş faktör yükleri öz sevecenlik için .52-.84, öz yargilama için .43- .82, paylaşımların bilincinde olma alt boyut için .58-.78, izolasyon alt ölçeği için .62-.77, bilinçlilik alt boyutu için .57-.82 ve aşırı özdeşleşme alt boyutu için .57-.82 arasında değişmektedir. Türkçe versiyonunun yapılan DFA'da elde modelin uyum indeksleri incelenmiş ve Ki-kare değerinin ( $\mathrm{x} 2=779.01$, $\mathrm{n}=633, \mathrm{sd}=264, \mathrm{p}=0.00$ ) anlamlı olduğu görülmüştür. Uyum indeksi değerleri ise $\mathrm{RMSEA}=.056, \mathrm{NFI}=.95, \mathrm{CFI}=.97, \mathrm{IFI}=.97, \mathrm{RFI}=.94, \mathrm{GFI}=.91$ ve $\mathrm{SRMR}=.059$ olarak bulunmuştur. Bu uyum indeksi değerleri modelin iyi uyum verdiğini göstermektedir. Türkçe ölçeğinin iç tutarlılık katsayıları sırasıyla; öz-sevecenlik alt ölçeği için .77, öz-yargılama için .72, paylaşımların bilincinde olma için .72, izolasyon için .80, bilinçlilik için .74 ve aşırı özdeşleşme için .74 olarak bulunmuştur. Test-tekrar test güvenirlik katsayıları öz-sevecenlik alt ölçeği için .69, öz-yargılama için .59, paylaşımların bilincinde olma için .66, izolasyon için .60, bilinçlilik için .69 ve aşırı özdeşleşme için .56 olarak bulunmuştur. Bu bulgular ışı̆̆ında Öz-duyarlılık ölçeğinin kabul edilebilir düzeyde geçerli ve güvenilir olduğu belirtilmiştir. Bu çalışmada ölçeğin iç tutarlılık güvenirlik katsayıları alt ölçekler için sırasıyla .78, .80, .75, .75, .72 ve .72 (öz-sevecenlik, öz-yargılama, paylaşımların bilincinde olma, yabancılaşma, bilinçlilik ve aşırı-özdeşleşme)'dir.

\section{Kişisel Bilgi Formu}

Araştırmacılar tarafından geliştirilen kişisel bilgi formunda demografik değişkenlere ait sorular (yaş, cinsiyet, medeni durum, eğitim durumu, maddi durum), olay değişkenlerine ait sorular (olay/olayların kendisi, olayın türü, olayın sıklığı, deneyimleme/maruz kalma şekli) ve bireysel etkilere (en çok etkileyen durum, etkilenme şiddeti, başa çıkma şekli, destek alıp alması) ait sorular yer almaktadır.

\section{Verilerin Analizi}

Araştırmada verilerin analizinde korelasyon ve çoklu regresyon analizi yöntemlerinden faydalanılmıştır. Regresyon analizi yapılmadan önce veri 
seti regresyon sayıltıları açısından incelenmiştir. Bu bağlamda çoklu bağlantı probleminin olup olmadığ korelasyon analizi ile incelenmiş̧ (Tablo 1) ve değişkenler arasında çoklu bağlantı probleminin olmadığı görülmüştür. Ayrıca regresyon analizinin diğer bir sayıltısı olan normallik ve doğrusallığın sağlanması için de Mahalanobis uzaklık değerleri saptanmış ve veri setinde çok değişkenli uç değerler olmadığı tespit edilmiştir. Doğrusallık ve normal dağılıma ilişkin bulgular Şekil 1'de; değişkenler arasında çoklu bağlantı probleminin olup olmadığını gösteren VIF değerleri de çoklu regresyon analizine ilişkin bulguların gösterildiği Tablo 2' de sunulmuştur.

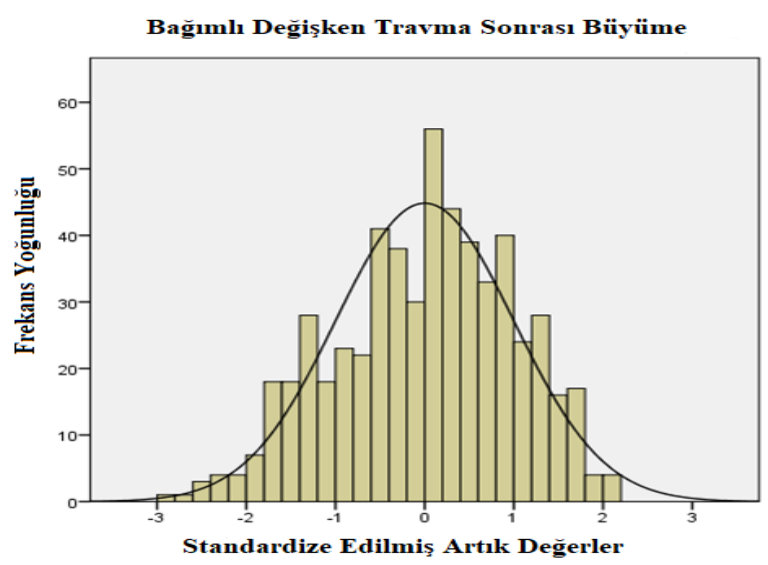

Şekil. 1. Standardize Edilmiş Bağımlı Değişken Travma Sonrası Büyümenin Normal Dağılım Grafiği

\section{Bulgular}

\section{Korelasyon Analizleri}

Araştırmada travma sonrası stres ve öz duyarlılık ile travma sonrası büyüme arasındaki ilişkiler Pearson korelasyon analizi ile incelenmiş ve bulgular Tablo 1'de sunulmuştur.

Tablo 1 incelendiğinde travma sonrası stres ile travma sonrası büyüme arasında pozitif yönde anlamlı ilişkili olduğu görülmektedir $(r=.23$, $\mathrm{p}<0.01)$. 
Tablo 1. Değişkenler Arasındaki Pearson Korelasyon Katsayıları

\begin{tabular}{llll}
\hline Değişkenler & $\mathbf{1}$ & $\mathbf{2}$ & $\mathbf{3}$ \\
\hline 1.Travma Sonrası Stres & 1 & $-.35^{* *}$ & $.23^{* *}$ \\
\hline 2.ÖD_Özduyarlılık & & 1 & $.13^{* *}$ \\
\hline 3.Travma Sonrası Büyüme & & & 1 \\
\hline$X^{-}$ & 53.66 & 14.98 & 2.70 \\
\hline$S S$ & 23.59 & 11.38 & .689 \\
\hline
\end{tabular}

${ }^{*} p<.05,{ }^{* *} p<.01$

Araştırmanın ilk denencesi (H1) desteklenmiştir. Benzer şekilde öz duyarlılık ile travma sonrası büyüme arasında pozitif anlamlı düzeyde ilişkili görülmektedir $(r=.13, \mathrm{p}<0.01)$. Araştırmanın ikinci denencesi $(\mathrm{H} 2)$ desteklenmiştir. Ancak öz duyarlılık ile travma sonrası stres arasında negatif anlamlı bir ilişki görülmektedir ( $r=-.35, \mathrm{p}<0.01)$. Araştırmanın üçüncü denencesi (H3) desteklenmiştir.

\section{Regresyon Analizleri}

Bu çalışmada travma sonrası stres ve öz duyarlılığın travma sonrası büyümeyi yordayıp yordamadığının ortaya çıkarılması amacıyla, elde edilen verilere çoklu regresyon analizi uygulanmıştır. Araştırmada değişkenler olarak; travma sonrası büyüme bağımlı değişken, travmatik stres ve öz-duyarlılık ise yordayıcı değişkenler olarak ele alınmıştır. Regresyon analizine ilişkin değerler Tablo 2' de verilmiştir.

Tablo 2. Travma Sonrası Büyümenin Yordanmasına Yönelik Yapılan Çoklu Regresyon Analizi

\begin{tabular}{lccccccc}
\hline Değişken & $\boldsymbol{B}$ & SS & $\boldsymbol{\beta}$ & $\boldsymbol{t}$ & $\boldsymbol{p}$ & $V I F$ & $\boldsymbol{R}^{2}$ \\
\hline Sabit & -.96 & .172 & & -5.5 & .000 & & \\
\hline Travma Sonrası Stres & .32 & .043 & .32 & 7.57 & .000 & 1.140 & \\
\hline Öz Duyarlılık & .35 & .062 & .24 & 5.74 & .000 & 1.140 & .106 \\
\hline
\end{tabular}

${ }^{{ }^{*} p<.05}$ 
Tablo 2 incelendiğinde travma sonrası stres $(\beta=.32, \mathrm{p}<0,01)$, ve öz duyarlılık $(\beta=.24, \mathrm{p}<0,01)$, travma sonrası büyümeyi anlamlı olarak yordadığ1 görülmektedir. Araştırmanın dördüncü denencesi (H4) desteklenmiştir. Regresyon modeli genel olarak değerlendirildiğinde her iki yordayıcı değişkenin travma sonrası büyüme puanının \%10'unu açıkladıkları görülmüş̧ür. $\left(R^{2}=.10, F(2,558)=34.11, p<.000\right)$.

\section{Tartışma}

$\mathrm{Bu}$ araştırma sonucunda, travma sonrası stres ve öz duyarlılı̆̆ın travma sonrası büyümeyi istatistiksel açıdan anlamlı düzeyde yordadıkları saptanmıştır. Yordayıcısı güçleri incelendiğinde travma sonrası stresin ve öz travma sonrası büyümede yordayıcı rolü sonucuna ulaşılmıştır.

$\mathrm{Bu}$ araştırma sonucuna göre ilk olarak travma sonrası büyüme ile travma sonrası stres arasında pozitif anlamlı bir ilişki bulunmuştur. Literatürdeki birçok çalışmada (Bleich ve ark., 2003; Butler ve ark., 2005; Dekel ve Hobfoll, 2007; Helgeson ve ark., 2006; Laufer ve Solomon, 2006), travma sonrası büyümenin travma sonrası stres belirtileri gösteren bireylerde görüldüğü ifade edilmiştir. Özellikle de travma sonrası büyümenin gerçekleşebilmesi için bireyin zorlu yaşam deneyiminden geçmesi ve bu yaşam deneyiminden etkilenmesi (bilişsel, duygusal, sosyal) gerektiğine yönelik bulgular ile paralellik göstermektedir (Bleich ve ark., 2003; Butler ve ark., 2005; Calhoun ve Tedeschi, 2014).

Travma sonrası stresi açıklayan kuramlarda bireyin zorlu deneyimle başa çıkarken bilişsel olarak sorguladığı ve bu sorgulamalar neticesinde çeşitli stratejiler geliştirdiği ifade edilmektedir. Bu sorgulamalar her ne kadar travma sonrası stresin araya girici düşünceleri, kaçınma davranışları ve uyarılmaları olarak ifade edilse de travma yaşayan bireyin kendilik algısı, ilişkiler ve yaşam felsefesinde değiş̧iklikleri, kısacası büyümelere yol açabilmektedir (Calhoun ve Tedeschi, 2014; Joseph ve Linley, 2005; Joseph ve ark., 2012). Literatürdeki araştırmalarda belirtilen bu bulgular, bu çalışmanın bir diğer sonucu olan travma sonrası stres puanlarının travma sonrası büyümeyi yordama gücünü açılar niteliktedir.

Ayrıca travma sonrası büyümeyi psikososyal yaklaşımlarla ele alan çalışmalarda (Armeli ve ark., 2001; Joseph ve Linley, 2005; O'Leary ve Ickovics, 1995; Tedeschi ve Calhoun, 2006; Waysman ve ark., 2001), travmadan 
etkilenirken bireyin hem aldığı sosyal destek kaynaklarından hem de kişisel özelliklerinden (özerlik, ilişkide olma vb.) dolayı yaşadığı travmanın üzerine düşünmesinin, anlamasının, ona göre yeni düzenlemeler yapmasının bireyin yaşadığı travmatik olaydan büyüyerek çıkmasını sağladığ vurgulanmaktadır. Literatürde (Maheux ve Price, 2016; Wong ve Yeung, 2017) bireyin bu travma deneyimini anlaması ve kabul etmesi için öz duyarlılı̆̆ın önemli bir etken olduğu ve öz duyarlılık ile travma sonrası büyüme arasında pozitif bir ilişki olduğu da belirtilmiştir. Bu bağlamda bu çalışmalar öz duyarlılık ve travma sonrası büyüme arasında bulunan pozitif ilişkiyi ve öz duyarlılığın travma sonrası büyümedeki yordayıcı rolünü destekler niteliktedir. Ayrıca literatürde öz duyarlılığının bireyin travmayı daha sağlıklı ele almasına yol açtığını ve travma sonrası stres ile öz duyarlılık arasında negatif bir ilişki olduğunu ortaya koyan çalışmalar da bulunmaktadır (Allen ve Leary, 2010; Germer ve Neff, 2015; Gilbert ve Procter, 2006; Kross ve Ayduk, 2011; Maheux ve Price, 2016; Neff, 2003b). Bu çalışmalar da bu çalışmadaki travma sonrası stres ile öz duyarlılık arasında bulunan negatif ilişki ile paraleldir.

Son olarak öz duyarlılığın hem travma sonrası stres hem de travma sonrası büyümede ilişkili olduğunu belirten çalışmalar (Gilbert ve Procter, 2006; Kross ve Ayduk, 2011; Maheux ve Price, 2016; Wong ve Yeung, 2017) ise hem travma sonrası stresin hem de öz duyarlılığın birlikte beraber ele alındığında travma sonrası büyümede yordama gücünü gözler önüne sermesini de desteklemektedir.

$\mathrm{Bu}$ araştırmanın sonuçları göz önünde bulundurulduğunda, çalışmanın çeşitli sınırlılıkları ve alana katkıları olduğu söylenebilir. Bu sınırlılıklar çerçevesinde gelecek araştırmalar için birtakım öneriler sunulabilir. Bu araştırmanın bulguları öz bildirime dayalı ölçeklerden elde edilmiş sonuçlarla sınırlıdır. Öz bildirime dayalı değerlendirmelerde bireylerin savunucu olma ve kendilerini iyi sunma eğiliminde olmasından dolayı sorulara verilen cevaplarda yanlılıklar olabileceği düşünülmektedir. Bu çalışmada kadın sayısı erkek sayısına oranla yüksektir. Bu bağlamda kadın ve erkek sayısının birbirine daha yakın olduğu bir çalışmada tekrar bu değişkenler test edilebilir. Üçüncü olarak, bu çalışmadaki bağımlı ve bağımsız değişken için olan veriler tek bir kaynaktan toplanmıştır. Podsakoff ve arkadaşlarına (2003) ve Antonakis ve arkadaşlarına (2010) göre bağımlı ve 
bağımsız değişkenlere ait verilerin aynı kaynaktan (sadece kişiden) toplanması, varyans sapma hatasını ortaya çıkarabilir. Varyans sapma hatasının olumsuz etkilerini azaltmak için çalışmadaki tüm ölçümlerin ayırt ediciliği test edilmiştir. Buna ek olarak, kesitsel tasarımın doğası gereği bu çalışmanın sonuçlarından bir nedensellik iddia edilemez.. Bu çalışmada, travma sonrası stres düzeyi tanı almayan normal popülasyondan elde edilen verilerle sınırlıdır. Bu bağlamda, bu bulgular travma sonrası stres düzeyi yüksek olan ve tanı alan klinik grupta da test edilebilir.

Ancak bütün bu sınırlılıklara rağmen bu araştırmanın sonuçları genel olarak değerlendirildiğinde, literatürdeki araştırma sonuçları ile paralellik göstermektedir. Kısacası dünyada giderek artan travmatik yaşantılar karşısında travma sonrası stresin ve öz duyarlılı̆̆ın travma sonrası büyümeyi açıklaması ile literatüre katkı sağlamış olabilir. Elde edilen bulgular doğrultusunda travma sonrası stres yaşayan bireylerin travma sonrası büyüme yaşayabilmeleri için öz duyarlılık odaklı programlar ve eğitimler gerçekleştirilebilir ve uygulanıp test edilebilir. 


\title{
EXTENDED ABSTRACT
}

\section{The Predictive Role of Posttraumatic Stress and Self Compassion on Posttraumatic Growth}

\author{
Neslihan Arıcı Özcan \\ İstanbul Medeniyet University
}

Today, post-traumatic stress disorder is seen in most of the individuals exposed to trauma (Kessler et al., 2014). There are many theories and models [cognitive models (Clark and Ehlers, 2004), the source model (Benight et al., 2000)]. In these models, it is common that trauma creates sensitivity in individual internal cognitive processes (Maheux and Price, 2016) and also focuses on the interaction of trauma and individual characteristics and differences within a psychosocial system such as personality, coping skills etc. (Joseph, Williams and Yule, 1997). When post-traumatic stress is explained both within the psychosocial system and within the individual's internal cognitive process, it can be seen the positive effects of trauma (Joseph and Linley, 2005).

Posttraumatic growth an individual experiencing positive psychological change in a challenging life experience (Tedeschi and Calhoun, 2004) requires moderate post-traumatic stress symptoms (Dekel and Hobfoll, 2007). In literatüre it is stated that the individual questions cognitively (intervening thoughts) while dealing with difficult experience and develops various strategies (avoidance and arousal) as a result of these interrogations. All these cognitive and behavioral situations can lead to changes in self-perception, relationships and philosophy of life and lead to post-traumatic growth (Janoff-Bulman, 2006). These changes in posttraumatic growth have been addressed by many studies within the psychosocial approach that consists of emotional, cognitive and resource (Armeli, Gunthert and Cohen, 2001).

It is important for the individual to accept new events in order to make new arrangements in his life and to use his internal and external resources (Bomyea, Risbrough and Lang, 2012). In this context, self-compassion is seen important. Self-compassion is that the individual is open to his / her own difficulties, the pain and emotions he / she experiences in the face of 
difficulties, and accepts them compassionately and without prejudice (Neff and McGehee, 2010). Self-compassion enables the individual to perceive his /her own experiences as a common human experience that everyone can live (Seligowski, Miron and Orcutt, 2015). In this context, there is a negative relationship between trauma and self-compassion. Self-compassion may affect the individual's perception of the traumatic event in a positive way, enable the individual to cope with the traumatic event and supports the post-traumatic growth (Neff and Vonk, 2009) When the related literature has been examined, it has been observed that the relationship between post-traumatic stress and self-compassion with various variables has been examined, but there have been few studies with post-traumatic growth (Wong and Yeung, 2017).

The aim of this study is to investigate the relationship among posttraumatic stress, posttraumatic growth and self-compassion in adult individuals. Post-traumatic Stress Disorder Scale, Self-Compassion Scale and Post-traumatic Growth Scale have been used to collect data. The participants are from the students at Faculty of Health Sciences in Istanbul Medeniyet University and their adult family members. The study group included total 561 participants, 426 women $(75.9 \%)$ and 135 men $(24.1 \%)$. The age of study group ranged from 18 to 67 year $(X=25.26)$. Correlation and regression analysis methods have been used in analysis.

As a result of the study, there has been a significant positive correlation between posttraumatic stress and posttraumatic growth $(r=.23, p<0.01)$. It is in line with the findings that post-traumatic growth requires an individual to go through a difficult life experience and be affected (Calhoun andTedeschi, 2014).The second result of the study is a significant positive correlation between self-compassion and post-traumatic growth $(r=.13$, $p<0.01$ ). In the literature (Maheux and Price, 2016; Wong and Yeung, 2017), a positive relationship between self-compassion and post-traumatic growth is supported by the findings of this study. However, there has been a negative correlation between self-compassion and post-traumatic stress $(r=-.35, p<0.01)$. In addition, studies suggesting a negative relationship between compassion and post-traumatic stress levels support the findings of this study (Germer and Neff, 2015). And post-traumatic stress ( $\beta$ $=.32, p<0.01)$ and self-compassion $(\beta=.24, \mathrm{p}<0.01)$ significantly have pre- 
dicted post-traumatic growth. When the regression model has been evaluated in general, it has been seen that both predictor variables explained $10 \%$ of the post-traumatic growth score. $\left(R^{2}=.10, \mathrm{~F}(2,558)=34.11, p<.000\right)$. Studies suggesting that self-compassion is correlated with both post-traumatic stress and post-traumatic growth (Maheux and Price, 2016; Wong andYeung, 2017) are in line with this finding of the study.

Lastly, the study has various limitations such as using self-report scales used, data from normal population etc. In spite of all these limitations, this study may have contributed to the literature by revealing the importance of post-traumatic stress, self-compassion and post traumatic growth.

\section{Kaynakça / References}

Akın, U., Akın, A. ve Abaci, R. (2007). Öz-duyarlık ölçeği: Geçerlik ve güvenirlik çalışması. Hacettepe Üniversitesi Ĕ̆itim Fakültesi Dergisi, 33(33), $1-10$.

Allen, A. B. ve Leary, M. R. (2010). Self-Compassion, stress, and coping. Social and Personality Psychology Compass, 4(2), 107-118.

Antonakis, J., Bendahan, S., Jacquart, P. ve Lalive, R. (2010). On making causal claims: A review and recommendations. The Leadership Quarterly, 21(6), 1086-1120.

APA, A. P. B. (2013). Mental Bozukluklarm Tanısal ve Sayımsal El Kitabı (DSM5) (K. E, Çev. 5. Baskı). Ankara: Hekimler Yayın Birliği.

Armeli, S., Gunthert, K. C. ve Cohen, L. H. (2001). Stressor appraisals, coping, and post-event outcomes: The dimensionality and antecedents of stress-related growth. Journal of Social and Clinical Psychology, 20(3), 366-395.

Barnard, L. K. ve Curry, J. F. (2011). Self-compassion: Conceptualizations, correlates and interventions. Review of General Psychology, 15(4), 289-303.

Benight, C. C., Freyaldenhoven, R. W., Hughes, J., Ruiz, J. M., Zoschke, T. A. ve Lovallo, W. R. (2000). Coping Self-Efficacy and Psychological Distress Following the Oklahoma City Bombing 1. Journal of Applied Social Psychology, 30(7), 1331-1344.

Bleich, A., Gelkopf, M. ve Solomon, Z. (2003). Exposure to terrorism, stress related mental health symptoms, and coping behaviors among a nationally representative sample in Israel. Jama, 290(5), 612-620. 
Bomyea, J., Risbrough, V. ve Lang, A. J. (2012). A consideration of select pretrauma factors as key vulnerabilities in PTSD. Clinical Psychology Review, 32(7), 630-641.

Brewin, C. R. ve Holmes, E. A. (2003). Psychological theories of post-traumatic stress disorder. Clinical Psychology Review, 23(3), 339-376.

Butler, L. D., Blasey, C. M., Garlan, R. W., McCaslin, S. E., Azarow, J., Chen,X. A. ve ark. (2005). Post-traumatic growth following the terrorist attacks of September 11, 2001: Cognitive, coping, and trauma symptom predictors in an internet convenience sample. Traumatology, 11, 247-26.

Calhoun, L. G. ve Tedeschi, R. G. (2014). The foundations of post-traumatic

growth: An expanded framework. In Handbook of post-traumatic growth (s. 1737). New York, NY: Routledge.

Clark, D. M. ve Ehlers, A. (2004). Post-traumatic stress disorder: From Cognitive Theory to Therapy. In (R. L. Leahy Ed.), Contemporary cognitive therapy: Theory, Research, and Practice (s. 141-160). New York: The Guilford Press.

Colville, G. ve Cream, P. (2009). Post-traumatic growth in parents after a child's admission to intensive care: maybe Nietzsche was right? Intensive Care Medicine, 35(5), 919-923.

Dalgleish, T. (2004). Cognitive approaches to posttraumatic stress disorder: The evolution of multi-representational theorizing. Psychological Bulletin, 130(2), 228.

Dekel, R. ve Hobfoll, S. (2007). The impact of resource loss on Holocaust survivors facing war and terrorism in Israel. Aging and Mental Health, 11(2), 159-167.

Dürü, C. (2006). Travma sonrası stres belirtileri ve travma sonrası büyümenin çeşitli değişkenler açısından incelenmesi ve bir model önerisi. Yayınlanmamış Doktora Tezi. Hacettepe Üniversitesi, Sosyal Bilimler Enstitüsü, Ankara.

Ehlers, A. ve Clark, D. M. (2000). A cognitive model of post-traumatic stress disorder.Behavioral Research Therapy, 38(4), 319-345.

Foa, E. B., Cashman, L., Jaycox, L. ve Perry, K. (1997). The validation of a selfreport measure of posttraumatic stress disorder: The Post-traumatic Diagnostic Scale. Psychological Assessment, 9(4), 445. 
Foa, E. B., Huppert, J. D. ve Cahill, S. P. (2006). Emotional processing theory: An Update. In B. O. Rothbaum (Ed.), Pathological anxiety: Emotional processing in etiology and treatment (s. 3-24). New York, NY, US: The Guilford Press.

Germer, C. K. ve Neff, K. D. (2015). Cultivating self-compassion in trauma survivors. In( V. M. Follette, J. Briere, D. Rozelle, J. W. Hopper, and D. I. Rome Ed.), Mindfulness-oriented interventions for trauma: Integrating contemplative practices (s. 43-58). New York, NY, US: The Guilford Press.

Gilbert, P. ve Procter, S. (2006). Compassionate mind training for people with high shame and self-criticism: Overview and pilot study of a group therapy approach. Clinical Psychology and Psychotherapy: An International Journal of Theory and Practice, 13(6), 353-379.

Helgeson, V. S., Reynolds, K. A. ve Tomich, P. L. (2006). A meta-analytic review of benefit finding and growth. Journal of Consulting and Clinical Psychology, 74(5), 797.

Hobfoll, S. E., Tracy, M. ve Galea, S. (2006). The impact of resource loss and traumatic growth on probable PTSD and depression following terrorist attacks. Journal of Traumatic Stress: Official Publication of The International Society for Traumatic Stress Studies, 19(6), 867-878.

Ironson, G., Wynings, C., Schneiderman, N., Baum, A., Rodriguez, M.,

Greenwood, D., . .., Huang, H.-S. ve ark. (1997). Post-traumatic stress symptoms, intrusive thoughts, loss, and immune function after Hurricane Andrew. Psychosomatic Medicine, 59(2), 128-141.

Janoff-Bulman, R. (2006). Schema-change perspectives on post-traumatic growth handbook of posttraumatic growth: Research and practice. (s. 81-99). Mahwah, NJ, US: Lawrence Erlbaum Associates Publishers.

Janoff-Bulman, R. (2006). Schema-change perspectives on post-traumatic growth. In (L. G. Calhoun and R. G. Tedeschi Ed.), Handbook of posttraumatic growth: Research and practice (s. 81-99). Mahwah, NJ, US: Lawrence Erlbaum Associates Publishers.

Joseph, S. ve Linley, P. A. (2005). Positive adjustment to threatening events: An organismic valuing theory of growth through adversity. Review of General Psychology, 9(3), 262-280.

Joseph, S., Murphy, D. ve Regel, S. (2012). An affective-cognitive processing model of post-traumatic growth. Clinical Psychology and Psychotherapy, 19(4), 316-325. 
Joseph, S., Williams, R. ve Yule, W. (1997). Understanding post-traumatic stress: A psychosocial perspective on PTSD and treatment. Wiley.

Karasar, N. (2012). Bilimsel Araştırma Yöntemi (22. Bask1). Ankara: Nobel Yayın Dağıtım.

Kessler, R. C. (2000). Post-traumatic stress disorder: the burden to the individual and to society. Journal of Clinical Psychiatry, 61, 4-12.

Kessler, R. C., Rose, S., Koenen, K. C., Karam, E. G., Stang, P. E., Stein, D. J., ... Viana, M. C. (2014). How well can post-traumatic stress disorder be predicted from pre-trauma risk factors? An exploratory study in the WHO World Mental Health Surveys. World Psychiatry, 13(3), 265274. https://doi.org/10.1002/wps.20150

Kross, E. ve Ayduk, O. (2011). Making meaning out of negative experiences by self-distancing. Current Directions in Psychological Science, 20(3), 187-191.

Kunst, M. (2010). Peri-traumatic distress, post-traumatic stress disorder symptoms, and posttraumatic growth in victims of violence. Journal of Trauma Stress, 23(4), 514-518.

Laufer, A. ve Solomon, Z. (2006). Post-traumatic symptoms and post-traumatic growth among Israeli youth exposed to terror incidents. Journal of Social and Clinical Psychology, 25(4), 429-447.

Maheux, A. ve Price, M. (2016). The indirect effect of social support on posttrauma psychopathology via self-compassion. Personality and Individual Differences, 88, 102-107.

Neff, K. D. (2003a). The development and validation of a scale to measure selfcompassion. Self and Identity, 2(3), 223-250.

Neff, K. D. (2003b). Self-compassion: An alternative conceptualization of a healthy attitude toward oneself. Self and Identity, 2(2), 85-101.

Neff, K. D. (2004). Self-compassion and psychological well-being. Constructivism in the Human Sciences, 9(2), 27.

Neff, K. D. ve McGehee, P. (2010). Self-compassion and psychological resilience among adolescents and young adults. Self and Identity, 9(3), 225240.

Neff, K. D. ve Vonk, R. (2009). Self-compassion versus global self-esteem: Two different ways of relating to oneself. Journal of Personality, 77(1), 23-50.

O'Leary, V. E. ve Ickovics, J. R. (1995). Resilience and thriving in response to challenge: an opportunity for a paradigm shift in women's health. Womens Health, 1(2), 121-142. 
Park, C. L., Mills, M. A. ve Edmondson, D. (2012). PTSD as meaning violation: Testing a cognitive worldview perspective. Psychological Trauma: Theory, Research, Practice, and Policy, 4(1), 66.

Podsakoff, P. M., MacKenzie, S. B., Lee, J.-Y. ve Podsakoff, N. P. (2003). Common method biases in behavioral research: A critical review of the literature and recommended remedies. Journal of Applied Psychology, 88(5), 879.

Raes, F. (2010). Rumination and worry as mediators of the relationship between self-compassion and depression and anxiety. Personality and Individual Differences, 48(6), 757-761.

Rauch, S. ve Foa, E. (2006). Emotional processing theory (EPT) and exposure therapy for PTSD. Journal of Contemporary Psychotherapy, 36(2), 61.

Seligowski, A. V., Miron, L. R. ve Orcutt, H. K. (2015). Relations among selfcompassion, PTSD symptoms, and psychological health in a traumaexposed sample. Mindfulness, 6(5), 1033-1041.

Tabachnick, B. G. and Fidell, L. S. (2015). Çok değiş̧kenli istatistiklerin kullanımı (Çev. Ed. M. Baloğlu). Ankara: Nobel.

Tedeschi, R. G. ve Calhoun, L. G. (1996). The Post-traumatic growth inventory: Measuring the positive legacy of trauma. Journal of Trauma Stress, 9(3), 455-471.

Tedeschi, R. G. ve Calhoun, L. G. (2004). Post-traumatic growth: Conceptual foundations and empirical evidence. Psychological Inquiry, 15(1), 1-18.

Tedeschi, R. G. ve Calhoun, L. G. (2006). Handbook of post-traumatic growth: Research and practice. Mahwah, NJ: Lawrence Erlbaum Associates.

Tedeshi, R. G. ve Calhoun, L. G. (1995). Trauma and transformation. Thousand Oaks, CA: Sage.

Thompson, B. L. ve Waltz, J. (2008). Self-compassion and PTSD symptom severity. Journal of Traumatic Stress: Official Publication of the International Society for Traumatic Stress Studies, 21(6), 556-558.

Waysman, M., Schwarzwald, J. ve Solomon, Z. (2001). Hardiness: An examination of its relationship with positive and negative long-term changes following trauma. Journal of Trauma Stress, 14(3), 531-548.

Wong, C. C. Y. ve Yeung, N. C. (2017). Self-compassion and post-traumatic growth: Cognitive processes as mediators. Mindfulness, 8(4), 10781087. 
Zatzick, D. F., Rivara, F. P., Nathens, A. B., Jurkovich, G. J., Wang, J., Fan, M.Y., ve ark. (2007). A nationwide US study of post-traumatic stress after hospitalization for physical injury. Psychological Medicine, 37(10), 1469-1480.

Zeller, M., Yuval, K., Nitzan-Assayag, Y. ve Bernstein, A. (2015). Self-compassion in recovery following potentially traumatic stress: Longitudinal study of at-risk youth. Journal of Abnormal Child Psychology, 43(4), 645653.

\section{Kaynakça Bilgisi / Citation Information}

Arıcı-Özcan, N. (2019). Yetişkinlerde travma sonrası stres ve öz duyarlılığın travma sonrası büyüme üzerindeki yordayıcı rolü. OPUSUluslararası Toplum Araştırmaları Dergisi, 14(20), 621-642. DOI: 10.26466/opus.594006 